\title{
Epitaxial growth of horizontally aligned single-crystal arrays of perovskite
}

\author{
Yitan $\mathrm{Li}^{1,2}$, Yuguang Chen ${ }^{1}$, Lu Han ${ }^{1}$, Xuemei $\mathrm{Li}^{3}$, Jian Sheng ${ }^{1}$, Hao Sun ${ }^{4}$ and Yan $\mathrm{Li}^{1,2^{*}}$
}

\begin{abstract}
Well-aligned single-crystal nanowire arrays of $\mathrm{CH}_{3} \mathrm{NH}_{3} \mathrm{PbI}_{3}$ have shown potentials in laser sources and photovoltaic applications. Here we developed a solution based epitaxial method to grow $\mathrm{CH}_{3} \mathrm{NH}_{3} \mathrm{PbI}_{3}$ nanowire arrays. By confining the precursor solution between a silicon wafer and ST-cut quartz, the evaporation rate of the solvent was slowed down which brings a more stable and controllable solution environment. Relying on the lattice match between $\mathrm{CH}_{3} \mathrm{NH}_{3} \mathrm{PbI}_{3}$ and ST-cut quartz, arrays of single-crystal nanowires of $\mathrm{CH}_{3} \mathrm{NH}_{3} \mathrm{PbI}_{3}$ have been grown epitaxially. The densities and lengths of $\mathrm{CH}_{3} \mathrm{NH}_{3} \mathrm{PbI}_{3}$ nanowires can be tuned. The lengths of the resultant crystals range from several microns to over one millimeter. Such $\mathrm{CH}_{3} \mathrm{NH}_{3} \mathrm{PbI}_{3}$ arrays with good alignment and crystallinity were then applied to fabricate photovoltaic devices with good performances.
\end{abstract}

Keywords: $\mathrm{CH}_{3} \mathrm{NH}_{3} \mathrm{PbI}_{3}$, single crystal, arrays, epitaxial growth, tunable lengths

\section{INTRODUCTION}

Well-organized single-crystal arrays on substrates are preferred for the fabrication of devices with high performances [1-4]. Such arrays have been realized by various strategies, among which epitaxy has shown great success in fabricating ordered crystalline nanostructures of giant magnetoresistance materials and semiconductors on specific substrates [5-10]. To date, most epitaxial growth processes are based on gas phase deposition at high temperature by using state-of-art facilities. Solutionbased material processing approaches are known to be flexible and cost-effective, and therefore have been broadly applied for the deposition of functional materials on substrates. However, it is still challenging to prepare well-aligned single-crystal arrays via solution pathways [11-16].

Lead halide perovskites, which are normally processed with solution based techniques or chemical vapor deposition process, have shown significant potentials for photovoltaic and electronic applications and drawn great attentions relying on the high absorption coefficients, balanced and long diffusion lengths, and ambipolar carrier transport properties [17-23]. Single-crystal perovskites with reduced-dimensional structures including nanoplates (NPs), nanowires (NWs) and quantum dots (QDs) have been applied in photonic and quantum devices such as single-photon sources [24], light-emitting diodes [25,26] and photodetectors [27-29]. In particular, low-dimensional perovskite crystals have shown to be good candidates for small solid-state laser at room temperature since the amplification of spontaneous emission (ASE) was firstly demonstrated by Xing et al. [30-34] in 2014. For such applications, alignment of the crystals is important. Recently, studies about perovskite epitaxy by chemical vapor deposition have been reported [23,28-29] while few of them are based on solution process.

In a previous study, we reported the crystal structure match of the (010) plane of $\mathrm{CH}_{3} \mathrm{NH}_{3} \mathrm{PbI}_{3}$ to the surface lattice of ST-cut quartz [35]. Both the lattice spacings of (001) and (101) planes of $\mathrm{CH}_{3} \mathrm{NH}_{3} \mathrm{PbI}_{3}$ and the crystal face angle fit the structural periodicity of ST-cut quartz. Utilizing this lattice match, aligned $\mathrm{CH}_{3} \mathrm{NH}_{3} \mathrm{PbI}_{3}$ crystals were obtained when precursor solutions were directly coated and evaporated on the ST-cut quartz. However, because of the unstable mass transport and random nucleation sites, it is difficult to obtain organized crystals with high quality and clean surface [36-38]. The crystal

\footnotetext{
${ }^{1}$ Key Laboratory for the Physics and Chemistry of Nanodevices, Beijing National Laboratory of Molecular Sciences, State Key Laboratory of Rare Earth Materials Chemistry and Applications, College of Chemistry and Molecular Engineering, Peking University, Beijing 100871, China

${ }^{2}$ Academy for Advanced Interdisciplinary Studies, Peking University, Beijing 100871, China

${ }^{3}$ Electron Microscopy Laboratory, Peking University, Beijing 100871, China

${ }^{4}$ Bruker (Beijing) Scientific Technology Co., Ltd., Beijing 100081, China

* Corresponding author (email: yanli@pku.edu.cn)
} 
qualities as well as the morphologies still need to be improved.

In open systems, the large gas-liquid interface area brings quick evaporation and fluid instabilities which are unfavorable for both the growth of high-quality crystals and the exerting of template effect of the substrate. On the other hand, a confined system has shown great advantage in harnessing the fluid behavior. Herein, we developed a method to realize the epitaxial crystal growth in confined solution systems. By restricting the precursor solution within the micrometer scaled space between two paralleled substrates ( $\mathrm{ST}$-cut quartz and $\mathrm{Si} / \mathrm{SiO}_{2}$ ), the evaporation rate of the solution is significantly reduced, making the crystallizing process more controllable. More importantly, meniscuses with tiny solution tips between two substrates are created, pushing the nucleation sites closer to the ST-cut quartz. Therefore, the template effect of the substrates can be well utilized. With this method, ultralong single-crystal $\mathrm{CH}_{3} \mathrm{NH}_{3} \mathrm{PbI}_{3}$ nanowire arrays with nearly perfect alignment and high qualities were obtained. The lengths and densities of $\mathrm{CH}_{3} \mathrm{NH}_{3} \mathrm{PbI}_{3}$ can be adjusted, showing the flexibility of our method.

\section{EXPERIMENTAL SECTION}

\section{Growth of $\mathrm{CH}_{3} \mathrm{NH}_{3} \mathrm{PbI}_{3}$ arrays and fabrication of photodetectors}

Typically, $0.2565 \mathrm{~g} \mathrm{CH}_{3} \mathrm{NH}_{3} \mathrm{I}$ (99.9\%, Dyesol, Australia) and $0.7435 \mathrm{~g} \mathrm{PbI}_{2}$ (AR, Aldrich) were dissolved in $3 \mathrm{~g}$ $\mathrm{N}, \mathrm{N}$-dimethylformamide (DMF, AR, Aldrich) to make a $\mathrm{CH}_{3} \mathrm{NH}_{3} \mathrm{PbI}_{3}$ precursor solution with a mass fraction of 25 wt.\% (0.1026 $\mathrm{g} \mathrm{CH}_{3} \mathrm{NH}_{3} \mathrm{I}$ and $0.2974 \mathrm{~g} \mathrm{PbI}_{2}$ in $3.6 \mathrm{~g}$ DMF for $\mathrm{CH}_{3} \mathrm{NH}_{3} \mathrm{PbI}_{3}$ precursor solution with a mass fraction of $10 \mathrm{wt} . \%)$. The precursor solution was sandwiched by ST-cut quartz and $\mathrm{Si} / \mathrm{SiO}_{2}$ with varying distances ranging from 20 to $300 \mu \mathrm{m}$. All the preparation processes were conducted in the glovebox under ambient temperature. A vacuum evaporator was used to deposit Ag layer with a thickness of $100 \mathrm{~nm}$ as the electrode of $\mathrm{CH}_{3} \mathrm{NH}_{3} \mathrm{PbI}_{3}$-based photodetectors.

\section{Characterizations}

The $\mathrm{CH}_{3} \mathrm{NH}_{3} \mathrm{PbI}_{3}$ nanowires grown on quartz were directly characterized with a cold-field emission scanning electron microscope (SEM-Hitachi S4800, operated at $2.0 \mathrm{kV}, 10 \mu \mathrm{A})$. The transmission electron microscopy (TEM) specimen was prepared by directly rubbing the grid on the substrates with products. The high resolution TEM (HRTEM) characterization was carried out on a FEI Tecnai G2 T20 microscope. A Dimension Icon SPM
(Bruker, Santa Barbara, CA, USA) was used to perform the AFM topographic measurements of the $\mathrm{CH}_{3} \mathrm{NH}_{3} \mathrm{PbI}_{3}$ arrays. The photo response performance of the devices was studied at ambient condition using a tungsten lamp.

\section{RESULTS AND DISCUSSION}

The setup of this confined epitaxial method was shown in Fig. 1a, where the $\mathrm{CH}_{3} \mathrm{NH}_{3} \mathrm{PbI}_{3}$ precursor solution was simply confined by two substrates $\left(\mathrm{Si} / \mathrm{SiO}_{2}\right.$ on top and ST-cut quartz at the bottom) with distances at micrometer scales. As the solution evaporated from side to central part, the distribution of concentration in the whole solution system varied. The tips of solution meniscuses reached saturation at first and then aligned $\mathrm{CH}_{3} \mathrm{NH}_{3} \mathrm{PbI}_{3}$ crystal nanowire arrays appeared as shown in Fig. 1b. When evaporating in the open air, the precursor solution coated on the ST-cut quartz experiences uniform evaporation, which often makes the nucleation sites away from the surface of ST-cut quartz. As shown in Fig. S1, irregular $\mathrm{CH}_{3} \mathrm{NH}_{3} \mathrm{PbI}_{3}$ arrays with poor alignment and wide size distributions were produced. It is observed that $\mathrm{CH}_{3} \mathrm{NH}_{3} \mathrm{PbI}_{3}$ microribbons interconnect with each other with rough surfaces.

In our method, the confinement setup decreased the
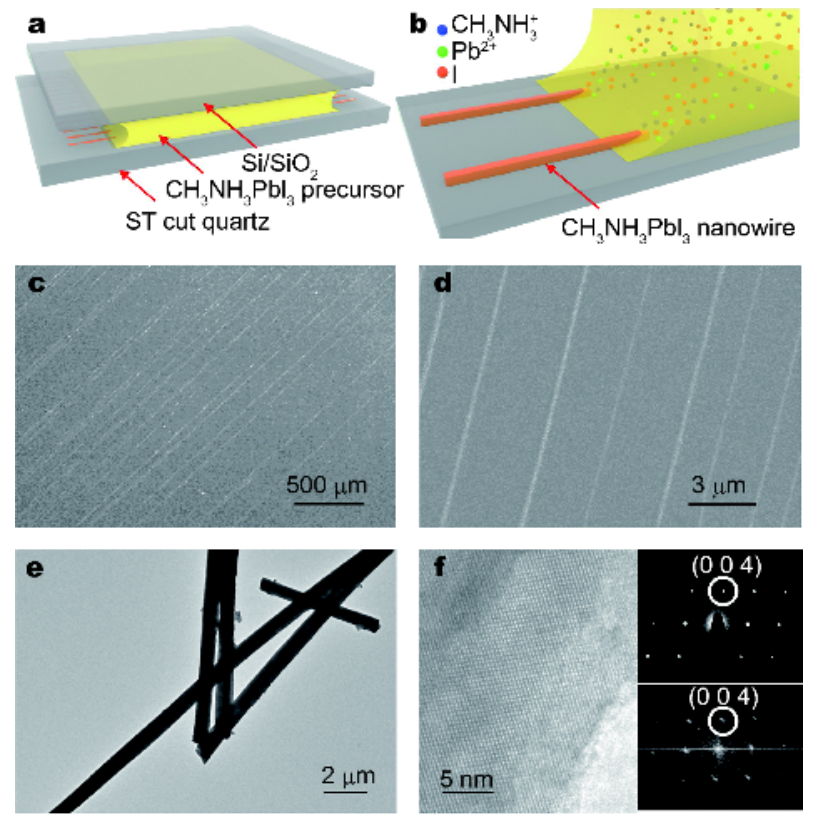

Figure $1(\mathrm{a}, \mathrm{b})$ Schematic illustrations of the growing process of aligned $\mathrm{CH}_{3} \mathrm{NH}_{3} \mathrm{PbI}_{3}$ nanowire arrays by the confined epitaxial method. (c, d) SEM images of $\mathrm{CH}_{3} \mathrm{NH}_{3} \mathrm{PbI}_{3}$ nanowire arrays at low (c) and high (d) magnifications. (e, f) TEM image (e) and HRTEM image (f) of singlecrystal $\mathrm{CH}_{3} \mathrm{NH}_{3} \mathrm{PbI}_{3}$ nanowires with selected area electron diffraction (SAED) patterns (up) and fast Fourier transform (FFT) patterns (down) inserted. 

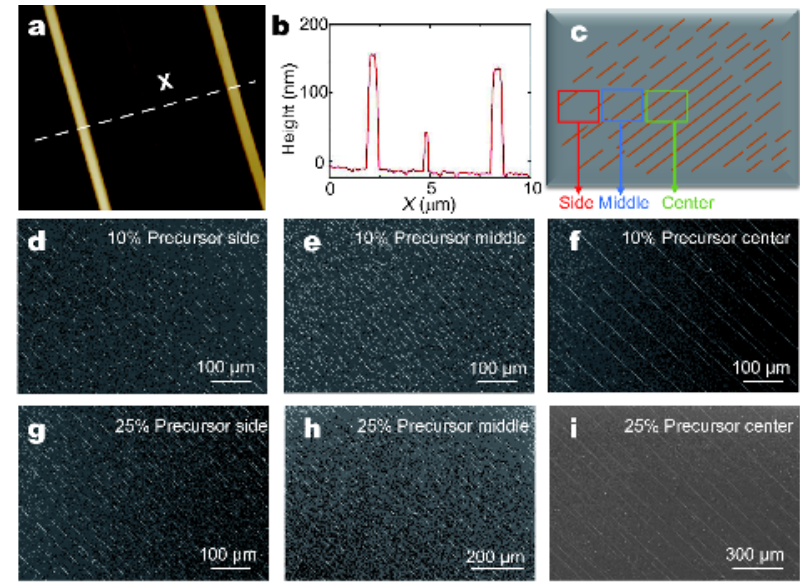

Figure $2(\mathrm{a}, \mathrm{b}) \mathrm{AFM}$ image (a) of $\mathrm{CH}_{3} \mathrm{NH}_{3} \mathrm{PbI}_{3}$ nanowires with height data (b). (c) Schematic illustration of the $\mathrm{CH}_{3} \mathrm{NH}_{3} \mathrm{PbI}_{3}$ arrays formed at different regions of the ST-cut quartz in the confined epitaxial growth process. (d-i) SEM images of $\mathrm{CH}_{3} \mathrm{NH}_{3} \mathrm{PbI}_{3}$ arrays grown from precursor solutions of different concentrations at different regions of the ST-cut quartz.

evaporating rate and limited most of the fluid flow in the solution to be laminar, providing a stable environment for the growth of high-quality single crystals. The meniscuses formed near the edges of solution bring the nucleation sites to the quartz substrate, increasing the template efficiencies. We were able to fabricate ultralong $\mathrm{CH}_{3} \mathrm{NH}_{3} \mathrm{PbI}_{3}$ nanowire arrays of millimeter scale on ST-cut quartz with good alignment (Fig. 1c, d). As shown in the TEM image in Fig. 1e, $\mathrm{CH}_{3} \mathrm{NH}_{3} \mathrm{PbI}_{3}$ wires have rectangular shapes and uniform sizes. The HRTEM image (Fig. 1f) exhibited fringes perpendicular to the longitudinal direction of the crystal with an inter-distance of $\sim 3.4 \AA$, which can be assigned to (004) planes [39-41]. These results indicated that the $\mathrm{CH}_{3} \mathrm{NH}_{3} \mathrm{PbI}_{3}$ nanowires were single crystals with high quality. It can be observed that both $\mathrm{CH}_{3} \mathrm{NH}_{3} \mathrm{PbI}_{3}$ nanowires and their surroundings are quite clean, indicating that almost all the materials in the precursor solution were utilized in the crystallization (Fig. 2a, b). These clean nanowires are favorable for building high performance electronic and photovoltaic devices.

The lengths of $\mathrm{CH}_{3} \mathrm{NH}_{3} \mathrm{PbI}_{3}$ nanowires can also be adjusted. Compared to the open system, our confined system introduces a more controllable lower evaporating rate. As the solution meniscuses move from edges to central parts, the evaporating rate decreases correspondingly due to the increased diffusion length for DMF vapor. (Fig. S2) It can be observed that $\mathrm{CH}_{3} \mathrm{NH}_{3} \mathrm{PbI}_{3}$ nanowires are longer at the central part of the substrate than those near the edges. (Fig. $2 \mathrm{~d}-\mathrm{f}$ ) The faster eva-
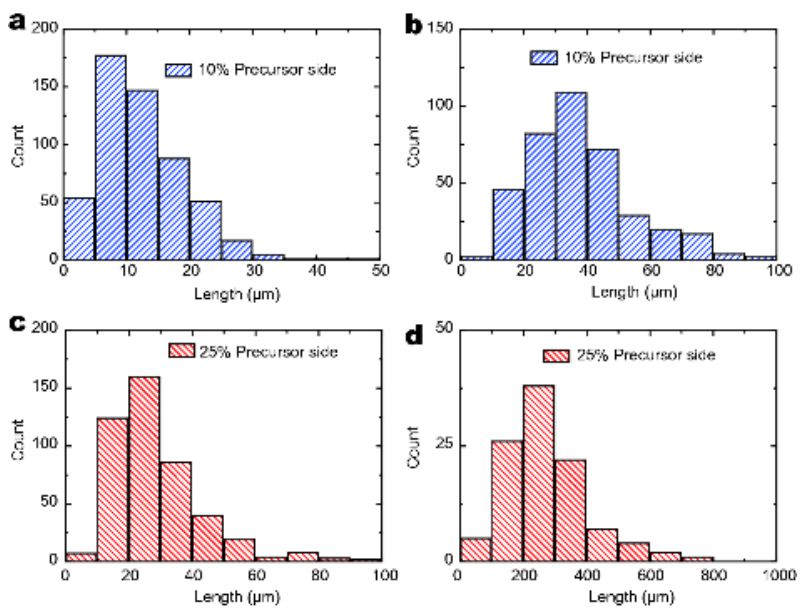

Figure 3 Length distributions of $\mathrm{CH}_{3} \mathrm{NH}_{3} \mathrm{PbI}_{3}$ nanowires at side parts (a, c) and middle parts $(b, d)$ of the ST-cut quartz which are grown from precursor solutions with concentrations of $10 \mathrm{wt} \%$ (a, b) and $25 \mathrm{wt} . \%$ (c, d), respectively.

poration at the beginning brings about a higher supersaturation and more nucleation sites. This is why shorter $\mathrm{CH}_{3} \mathrm{NH}_{3} \mathrm{PbI}_{3}$ wires were obtained in the margin region. On the contrary, slower evaporation results in fewer nuclei and eventually longer wires with low density are obtained. The initiate concentration of precursor solution also affects the length and density of the wires. (Fig. $2 \mathrm{~g}-\mathrm{i}$ )

To statistically characterize the length distributions of $\mathrm{CH}_{3} \mathrm{NH}_{3} \mathrm{PbI}_{3}$ nanowires at different regions and grown from precursor solutions with different concentrations, we measured more than one thousand $\mathrm{CH}_{3} \mathrm{NH}_{3} \mathrm{PbI}_{3}$ nanowires in total (Fig. 3). From side parts to middle parts of ST-cut quartz, the average lengths of $\mathrm{CH}_{3} \mathrm{NH}_{3} \mathrm{PbI}_{3}$ nanowires increased from $12.5 \mu \mathrm{m}$ to $38.0 \mu \mathrm{m}$ (Fig. 3a, b) for $10 \mathrm{wt} . \%$ precursor solution and from $28.9 \mu \mathrm{m}$ to $276.8 \mu \mathrm{m}$ (Fig. 3c, d) for $25 \mathrm{wt} . \%$ precursor solution. In fact, at central parts, we found that the lengths of $\mathrm{CH}_{3} \mathrm{NH}_{3} \mathrm{PbI}_{3}$ nanowires could reach more than $500 \mu \mathrm{m}$ for $10 \mathrm{wt} . \%$ precursor solution and more than $1.5 \mathrm{~mm}$ for $25 \mathrm{wt} . \%$ precursor solution. In addition, $\mathrm{CH}_{3} \mathrm{NH}_{3} \mathrm{PbI}_{3}$ nanowires tend to grow denser as the concentration of solution increases.

To further illustrate the importance of confinement, we changed the distances between two substrates from 20 to $300 \mu \mathrm{m}$ (Fig. S3). As the distances between two substrates increased, the $\mathrm{CH}_{3} \mathrm{NH}_{3} \mathrm{PbI}_{3}$ crystals became less ordered and eventually disordered. This result can be ascribed to the change of the guiding efficiency of the substrate to the crystal formation of the materials. As the distance increases, the size and shape of meniscus change, bringing 
a
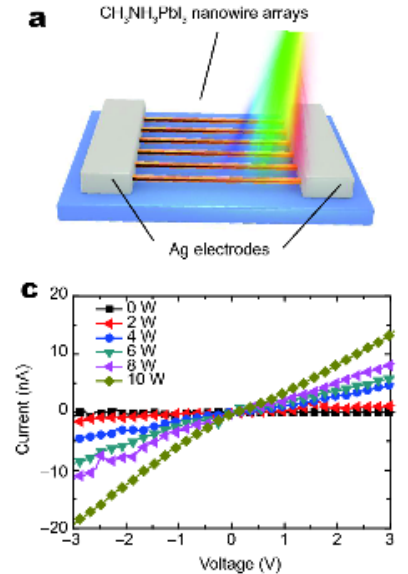

b
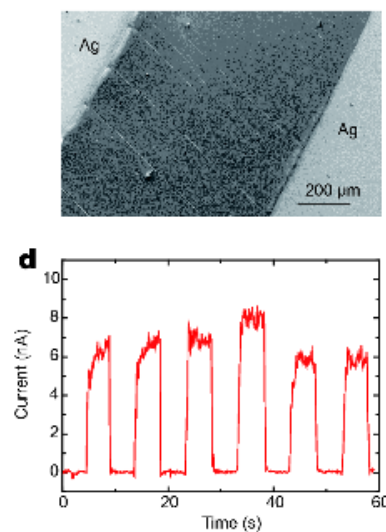

Figure 4 (a, b) Schematic illustration (a) and corresponding SEM image (b) of a $\mathrm{CH}_{3} \mathrm{NH}_{3} \mathrm{PbI}_{3}$ nanowire array based photodetector. (c, d) $I-V$ (c) and $I-t$ (d) curves of photo response performances of the $\mathrm{CH}_{3} \mathrm{NH}_{3} \mathrm{PbI}_{3}$ based photodetector.

the nucleation farther away the substrate. In addition, the vessel contains more solution when the distance between the two slides is bigger. When the $\mathrm{CH}_{3} \mathrm{NH}_{3} \mathrm{PbI}_{3}$ arrays formed, new nucleation may happen in the excessive saturated solution, resulting in poor morphologies (Fig. S3f).

Due to the ultrafast charge generation, high mobility, long charge carrier lifetime and diffusion length [42-45], $\mathrm{CH}_{3} \mathrm{NH}_{3} \mathrm{PbI}_{3}$ single crystal arrays showed potentials for photodetector applications. We directly evaporate $100 \mathrm{~nm}$ $\mathrm{Ag}$ on the substrate as electrodes to fabricate long channel photodetectors and study their photoresponsive performances (Fig. 4). The channel length between two electrodes was about $800 \mu \mathrm{m}$. This long channel is beneficial to suppressing dark current and responsible for improving the detectivity of photodetectors. We measured $I-V$ curves under incident light with power varying from 0 to $10 \mathrm{~W}$ and $I-t$ curves under an ON/OFF interval of $\sim 10 \mathrm{~s}$. The photo response time was measured to be $\sim 50 \mathrm{~ms}$, which actually already reached the limitation of our detector. In addition, when we annealed the sample under $80^{\circ} \mathrm{C}$ for $2 \mathrm{~h}$, there was no obvious change in photoresponsive performances, indicating the stability of the $\mathrm{CH}_{3} \mathrm{NH}_{3} \mathrm{PbI}_{3}$ nanowires endowed by the high crystallinity.

\section{CONCLUSIONS}

In summary, large-scale single-crystal $\mathrm{CH}_{3} \mathrm{NH}_{3} \mathrm{PbI}_{3}$ nanowire arrays have been grown on the ST-cut quartz via an epitaxial process in a confined solution system. Besides the lattice match between $\mathrm{CH}_{3} \mathrm{NH}_{3} \mathrm{PbI}_{3}$ and
ST-cut quartz, the confinement of the solution is also essential for the epitaxy. The precursor solution was sandwiched by a $\mathrm{Si} / \mathrm{SiO}_{2}$ wafer and a ST-cut quartz substrate, creating solution meniscuses with small tips contacting the substrates. Therefore the nucleation occurs on the ST-cut quartz then the further crystallization is templated by the substrate, resulting in high-quality $\mathrm{CH}_{3} \mathrm{NH}_{3} \mathrm{PbI}_{3}$ nanowire arrays. The lengths of $\mathrm{CH}_{3} \mathrm{NH}_{3} \mathrm{PbI}_{3}$ nanowires can be adjusted from several microns to a subcentimeter scale with nearly perfect alignment and a narrow distribution of diameters. The well-aligned single-crystal perovskite nanowire arrays may find applications in electronic devices, sensors, and lasers.

Received 23 April 2018; accepted 30 May 2018;

published online 28 June 2018

1 Khang DY, Jiang H, Huang Y, et al. A stretchable form of singlecrystal silicon for high-performance electronics on rubber substrates. Science, 2006, 311: 208-212

2 Duan X, Niu C, Sahi V, et al. High-performance thin-film transistors using semiconductor nanowires and nanoribbons. Nature, 2003, 425: 274-278

3 Li H, Tee BCK, Giri G, et al. High-performance transistors and complementary inverters based on solution-grown aligned organic single-crystals. Adv Mater, 2012, 24: 2588-2591

4 Briseno AL, Mannsfeld SCB, Ling MM, et al. Patterning organic single-crystal transistor arrays. Nature, 2006, 444: 913-917

5 Baibich MN, Broto JM, Fert A, et al. Giant magnetoresistance of (001) $\mathrm{Fe} /(001) \mathrm{Cr}$ magnetic superlattices. Phys Rev Lett, 1988, 61: 2472-2475

6 Binasch G, Grünberg P, Saurenbach F, et al. Enhanced magnetoresistance in layered magnetic structures with antiferromagnetic interlayer exchange. Phys Rev B, 1989, 39: 4828-4830

7 Park WI, Yi GC, Jang HM. Metalorganic vapor-phase epitaxial growth and photoluminescent properties of $\mathrm{Zn}_{1-x} \mathrm{Mg}_{x} \mathrm{O}$ $(0 \leq x \leq 0.49)$ thin films. Appl Phys Lett, 2001, 79: 2022-2024

8 Haury A, Wasiela A, Arnoult A, et al. Observation of a ferromagnetic transition induced by two-dimensional hole gas in modulation-doped CdMnTe quantum wells. Phys Rev Lett, 1997, 79: 511-514

9 Zhang Y, Chang TR, Zhou B, et al. Direct observation of the transition from indirect to direct bandgap in atomically thin epitaxial $\mathrm{MoSe}_{2}$. Nat Nanotechnol, 2014, 9: 111-115

10 Geim AK, Grigorieva IV. van der Waals heterostructures. Nature, 2013, 499: 419-425

11 Giri G, Verploegen E, Mannsfeld SCB, et al. Tuning charge transport in solution-sheared organic semiconductors using lattice strain. Nature, 2011, 480: 504-508

12 Diao Y, Shaw L, Bao Z, et al. Morphology control strategies for solution-processed organic semiconductor thin films. Energy Environ Sci, 2014, 7: 2145-2159

13 Diao Y, Tee BCK, Giri G, et al. Solution coating of large-area organic semiconductor thin films with aligned single-crystalline domains. Nat Mater, 2013, 12: 665-671

14 Minemawari $\mathrm{H}$, Yamada $\mathrm{T}$, Matsui $\mathrm{H}$, et al. Inkjet printing of 
single-crystal films. Nature, 2011, 475: 364-367

15 Arias AC, MacKenzie JD, McCulloch I, et al. Materials and applications for large area electronics: solution-based approaches. Chem Rev, 2010, 110: 3-24

16 Yuan Y, Giri G, Ayzner AL, et al. Ultra-high mobility transparent organic thin film transistors grown by an off-centre spin-coating method. Nat Commun, 2014, 5: 3005

17 Park NG. Organometal perovskite light absorbers toward a 20\% efficiency low-cost solid-state mesoscopic solar cell. J Phys Chem Lett, 2013, 4: 2423-2429

18 Grätzel M. The light and shade of perovskite solar cells. Nat Mater, 2014, 13: 838-842

19 Snaith HJ. Perovskites: the emergence of a new era for low-cost, high-efficiency solar cells. J Phys Chem Lett, 2013, 4: 3623-3630

20 Ding J, Yan Q. Progress in organic-inorganic hybrid halide perovskite single crystal: growth techniques and applications. Sci China Mater, 2017, 60: 1063-1078

21 Wang Y, Liu D, Zhang P, et al. Reveal the growth mechanism in perovskite films via weakly coordinating solvent annealing. Sci China Mater, 2018, 61: 1536-1548

22 Ding X, Ren Y, Wu Y, et al. Sequential deposition method fabricating carbonbased fully-inorganic perovskite solar cells. Sci China Mater, 2018, 61: 73-79

23 Chen YX, Ge QQ, Shi Y, et al. General space-confined on-substrate fabrication of thickness-adjustable hybrid perovskite single-crystalline thin films. J Am Chem Soc, 2016, 138: 16196-16199

24 Park YS, Guo S, Makarov NS, et al. Room temperature singlephoton emission from individual perovskite quantum dots. ACS Nano, 2015, 9: 10386-10393

25 Shi Z, Li Y, Zhang Y, et al. High-efficiency and air-stable perovskite quantum dots light-emitting diodes with an all-inorganic heterostructure. Nano Lett, 2017, 17: 313-321

26 Pan J, Quan LN, Zhao Y, et al. Highly efficient perovskite-quantum-dot light-emitting diodes by surface engineering. Adv Mater, 2016, 28: 8718-8725

27 Liu C, Wang K, Du P, et al. Ultrasensitive solution-processed broad-band photodetectors using $\mathrm{CH}_{3} \mathrm{NH}_{3} \mathrm{PbI}_{3}$ perovskite hybrids and $\mathrm{PbS}$ quantum dots as light harvesters. Nanoscale, 2015, 7: 16460-16469

28 Shoaib M, Zhang X, Wang X, et al. Directional growth of ultralong $\mathrm{CsPBBr}_{3}$ perovskite nanowires for high-performance photodetectors. J Am Chem Soc, 2017, 139: 15592-15595

29 Chen J, Morrow DJ, Fu Y, et al. Single-crystal thin films of cesium lead bromide perovskite epitaxially grown on metal oxide perovskite $\left(\mathrm{SrTiO}_{3}\right)$. J Am Chem Soc, 2017, 139: 13525-13532

30 Xing G, Mathews N, Lim SS, et al. Low-temperature solutionprocessed wavelength-tunable perovskites for lasing. Nat Mater, 2014, 13: 476-480

31 Deschler F, Price M, Pathak S, et al. High photoluminescence efficiency and optically pumped lasing in solution-processed mixed halide perovskite semiconductors. J Phys Chem Lett, 2014, 5: 1421-1426

32 Zhu H, Fu Y, Meng F, et al. Lead halide perovskite nanowire lasers with low lasing thresholds and high quality factors. Nat Mater, 2015, 14: 636-642
33 Eaton SW, Lai M, Gibson NA, et al. Lasing in robust cesium lead halide perovskite nanowires. Proc Natl Acad Sci USA, 2016, 113: 1993-1998

34 Zhang Q, Ha ST, Liu X, et al. Room-temperature near-infrared high-Q perovskite whispering-gallery planar nanolasers. Nano Lett, 2014, 14: 5995-6001

35 Li Y, Wang $\mathrm{X}, \mathrm{Wu} \mathrm{S}$, et al. Large-scale aligned crystalline $\mathrm{CH}_{3} \mathrm{NH}_{3} \mathrm{PbI}_{3}$ perovskite array films. J Mater Chem A, 2015, 3: 18847-18851

36 Pimpinelli A, Villain J, Physics of Crystal Growth. Cambridge: Cambridge University Press, 1998, Vol. 19

37 Hurle D T, Handbook of Crystal Growth. Amsterdam: Elsevier, 1993, Vol. 1

38 Lan CW, Kou S. Heat transfer, fluid flow and interface shapes in floating-zone crystal growth. J Cryst Growth, 1991, 108: 351-366

39 Zhou Y, Yang M, Wu W, et al. Room-temperature crystallization of hybrid-perovskite thin films via solvent-solvent extraction for high-performance solar cells. J Mater Chem A, 2015, 3: 8178-8184

40 Yang $\mathrm{M}$, Zhou $\mathrm{Y}$, Zeng $\mathrm{Y}$, et al. Square-centimeter solution-processed planar $\mathrm{CH}_{3} \mathrm{NH}_{3} \mathrm{PbI}_{3}$ perovskite solar cells with efficiency exceeding 15\%. Adv Mater, 2015, 27: 6363-6370

41 Im JH, Lee CR, Lee JW, et al. 6.5\% efficient perovskite quantumdot-sensitized solar cell. Nanoscale, 2011, 3: 4088-4093

42 Ponseca Jr. CS, Savenije TJ, Abdellah M, et al. Organometal halide perovskite solar cell materials rationalized: ultrafast charge generation, high and microsecond-long balanced mobilities, and slow recombination. J Am Chem Soc, 2014, 136: 5189-5192

$43 \mathrm{Fu} \mathrm{Y,} \mathrm{Zhu} \mathrm{H,} \mathrm{Stoumpos} \mathrm{CC,} \mathrm{et} \mathrm{al.} \mathrm{Broad} \mathrm{wavelength} \mathrm{tunable} \mathrm{robust}$ lasing from single-crystal nanowires of cesium lead halide perovskites $\left(\mathrm{CsPbX}_{3}, \mathrm{X}=\mathrm{Cl}, \mathrm{Br}, \mathrm{I}\right)$. ACS Nano, 2016, 10: 7963 7972

44 Saidaminov MI, Abdelhady AL, Maculan G, et al. Retrograde solubility of formamidinium and methylammonium lead halide perovskites enabling rapid single crystal growth. Chem Commun, 2015, 51: 17658-17661

45 Zhang $\mathrm{Y}, \mathrm{Du} \mathrm{J}, \mathrm{Wu} \mathrm{X}$, et al. Ultrasensitive photodetectors based on island-structured $\mathrm{CH}_{3} \mathrm{NH}_{3} \mathrm{PbI}_{3}$ thin films. ACS Appl Mater Interfaces, 2015, 7: 21634-21638

Acknowledgements This research is financially supported by the National Natural Science Foundation of China (21631002, U1632119, 21621061, and 91633301) and Ministry of Science and Technology of the People's Republic of China (2016YFA0201904).

Author contributions $\quad \mathrm{Li}$ YT and Li Y designed the experiments; Li YT, Chen Y, Han L and Sheng J engineered the samples and performed the experiments; Li X conducted the characterization of TEM; Sun $\mathrm{H}$ provided guidance in AFM characterization. Li YT and Li Y wrote and polished the manuscript.

Conflict of interest The authors declare no conflict of interest.

Supplementary information Supporting data are available in the online version of the paper. 

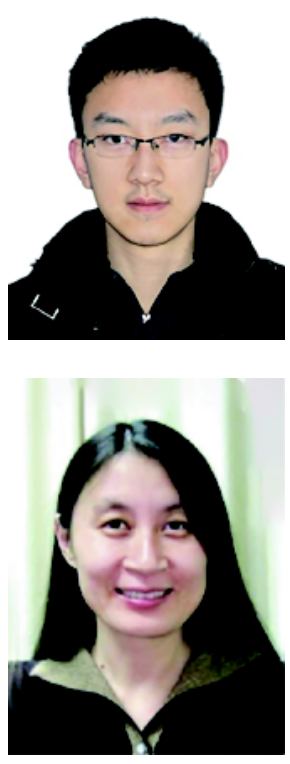

Yitan Li received the BSc degree in Physics from Shandong University in 2014. He then joined Peking university and became a PhD candidate in Prof. Yan Li's Research Group.
Yan Li is currently a Chang Jiang professor in the College of Chemistry and Molecular Engineering, Peking University. She received her PhD degree in inorganic chemistry from Peking University in 1993 and joined the Faculty of Peking University in 1995. From Nov. 1999 to May 2001, she was a visiting associate professor in Duke University, USA. She was promoted to a full professor in 2002. She also holds a distinguished visiting professor position in the University of Tokyo. She is an associate editor of ACS Nano and on editorial boards of several other journals. Her research focuses on the preparation, characterization, properties, and applications of functional nanomaterials and nanostructures.

\section{利用外延生长构建水平单晶锭钛矿阵列}

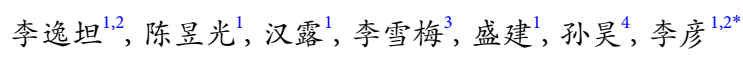

摘要 有序单晶 $\mathrm{CH}_{3} \mathrm{NH}_{3} \mathrm{PbI}_{3}$ 钻钛矿纳米线阵列在激光和光电领域具有良好的应用前景. 溶液法被认为是一种简便、高效且成本低廉的方 法并被用于构建䥻铁矿晶体材料. 本文介绍了一种限域外延生长方法并将其用于构建有序单晶 $\mathrm{CH}_{3} \mathrm{NH}_{3} \mathrm{PbI}_{3}$ 钙钛矿纳米线阵列. 通过将钲 钛矿材料的前驱体溶液限制在由硅片和ST-cut的石英构成的反应腔中, 溶液挥发行为受到限制, 进而为晶体生长提供了更加稳定可控的 环境. 由于 $\mathrm{CH}_{3} \mathrm{NH}_{3} \mathrm{PbI}_{3}$ 和 ST-cut石英之间存在晶格匹配, 可以在石英表面获得密集的单晶钙钛矿纳米线阵列. 通过调节反应腔尺寸, 可以 进一步调控钻钛矿纳米线的长度, 获得长度为由微米尺寸到亚厘米尺寸不等的阵列. $\mathrm{CH}_{3} \mathrm{NH}_{3} \mathrm{PbI}_{3}$ 钻钛矿阵列进一步被用于光电器件的构 建并获得了较好的性能. 